\title{
THERMODYNAMIC MODELLING OF HIGH- TEMPERATURE SYNTHESIS OF THE TITAN AND CHROME CARBIDES ON AN ALLOYED STEEL FOR ELECTRON-BEAM MELTING OF MODIFYING COATINGS
}

\author{
Sergey Kornilov ${ }^{1}$, Nikolay Rempe ${ }^{1}$, Natalia Smirnyagina ${ }^{1,2,}{ }^{*}$, Valentina Khaltanova ${ }^{2,3}$, \\ Anna Lapina ${ }^{2}$ \\ ${ }^{1}$ Tomsk State University of Control Systems and Radioelectronics, 634050, Tomsk, Russia \\ ${ }^{2}$ Institute of Physical Materials Science SB of the RAS, 670047, Ulan-Ude, Russia \\ ${ }^{3}$ Buryat State University, 670000, Ulan-Ude, Russia
}

\begin{abstract}
Adiabatic temperatures of interaction and equilibrium phase compositions in the 300-2673 $\mathrm{K}$ temperature range are determined by thermodynamic calculations made for a interaction of titan and chrome oxides with carbon on a surface of the alloyed steel 321 at non vacuum electron-beam melting. Synthesized phases are found to be thermodynamically stable refractory compounds - oxides, carbides, nitrides $\mathrm{Cr}, \mathrm{Ti}, \mathrm{Fe}$ and, stable in contact with the solid-state metallic base.
\end{abstract}

\section{Introduction}

Thermodynamic modeling (TM) is a universal method of research, which is widely applied at formation of new metal, ceramic and composite materials and work out new effective, recourse - and energy saving up methods of their synthesis. For example, for calculation of binary and multicomponent diagrams of phase balance, which are a basis for running out of new alloys and make one of the major bases of materials science, method CALPHAD (Calculation of Phase Diagrams) [1-3] is used. Modeling of an equilibrium status in multicomponent multiphase chemically reacting systems is applied to process out and optimization of many processes of synthesis of inorganic substances in materials technology and various areas of chemical technology [4, 5]. Thus, TM spend in various modes, for example, isobar-isothermal, adiabatic, etc. also use various computer methods and specialized programs $[2,4,5]$. TM allows to define equilibrium composition of interaction products (gaseous and condensed) in multicomponent heterogeneous systems; temperature of chemically reacting system in adiabatic conditions (i.e. without taking into account heat of loss in environment) to estimate influence of various factors on an exit of a product and to create a basis for description of the probable mechanism of physical and

Corresponding author: smirnyagina09@mail.ru 
chemical interaction, phase - and structure formation in difficult systems at synthesis and operation of new materials.

With position to synthesis of new materials, TM it has been successfully used by working out and optimization of reaction processes of multicomponent powder sating environments by an aluminothermy method for the subsequent formation of wear proof carbides coatings on carbonaceous steels by thermochemical treatment [6]. The thermodynamic modeling applied in present study, is the important stage at formation of composite materials and the processes of their reception based on the phenomenon of selfextending high-temperature synthesis (SHS) [7-9].

The purpose of the work was interaction consideration between components of heterogeneous powder compositions on a basis the titan and chrome oxides with carbon on a surface of the alloyed steel at atmospheric pressure, an establishment of equilibrium phase composition and forecasting of thermal stability of the titan and chrome carbides in a wide interval of the temperatures which top value corresponds to a metal-basis melting point. Modelling of possible phase and chemical transformations at SHS process and electronbeam melting of SHS products on an alloyed steel surface at formation of a composite layer of the titan and chrome carbides of the thickness 100 microns on air.

\section{Substantiation of a thermodynamic modelling technique}

The adiabatic temperature $T_{a d}$ of interaction is the important characteristic in SHS processes. Last years for TM use computer programs with thermodynamic databases (TD) which are based on search of a minimum of Gibbs energy of multiphase multicomponent system $[4,5,10-13]$. Thus, TM it is reduced to search in TD compounds, which can be formed of the elements, which are a part of initial substances, and to formation of their quantitative parity responding balance under set conditions. For SHS processes in multicomponent systems at the Institute of Structural Macrokinetics, Russian Academy of Sciences and problems of materials technology of the Russian Academy of Sciences (Russian acronym ISMAN) develops specialized program ISMAN-TERMO which allows to spend TM only in adiabatic mode $[8,9]$.

\subsection{Universal program ASTRA-4}

Developed in Bauman state technical university the universal program ASTRA-4 carries out search of the equilibrium composition responding a condition of a local maximum of entropy of system $\mathrm{S}$ in the presence restrictions (a condition of weight continuation of each element and full internal energy of system) for the set initial composition and a thermodynamic parameter $[10,11]$. TD of programs ASTRA-4 it is based on reference books on thermodynamics of individual substances [12-19] and contains of the big number of inorganic compounds.

The application technique of program ASTRA-4 for TM synthesis of materials in a adiabatic mode has been developed earlier with reference to classical SHS processes [20] and to synthesis of powder compositions for thermochemical treatment of steels. It contains on carrying out of a calculations series taking into account all possible binary diagram's $[21,22]$ and introduction in TD new compounds (absent in a standard configuration). The composition of the products received at system cooling after synthesis from temperature $T_{a d}$ to room, can differ from equilibrium composition at $T_{a d}$. Therefore, further it is spent TM in isobar-isothermal conditions at temperature below points of phase transformations in the multicomponent system. At each stage calculations are carried out some times, i.e. it is iterative, taking into account temperature areas of existence of those or other phasesproducts. 


\subsection{Computer program TERRA}

In the present work for TM computer program TERRA which represents the new version of program ASTRA-4 is used. Program TERRA is intended for work in Windows system and possesses new options for situation with TD, more expedient interface and the extended possibilities for presentation of calculations [23].

The software of complex Terra for calculation of chemical reactions starts with various conditions of balance: achievements of a minimum of Gibbs energy and an entropy maximum.

In the first case, the optimizing problem presented in general, a kind condition

$$
\Delta G_{\text {reaction }}^{o} \rightarrow \min ; \sum_{i, j}^{\mathrm{Nn}} C_{i, j} X_{j} \leq b_{i},
$$

where $b_{i}$ certain quantity of reacting chemical element $B_{i} ; X_{i}$ stoichiometric factor of $j$ compound, $C_{i, j}$ - quantity of atoms $B_{i}$ in compound $j, N$ - quantity of the chemical elements participating in reaction; $n$ - quantity of reaction products.

In the second case, calculation is worked out, preceding from conditions of entropy maximum $S \rightarrow S_{\max }$, a constancy of full internal energy, presentation of the continuation law of weight of all chemical elements, acquiescence of a gas phase to the composition equation for a mix of ideal gases.

A problem formulation of thermodynamic modelling demands to appoint two conditions of balance of studied system with environment. These conditions can be or numerical values of thermodynamic characteristics of equilibrium, or functional parities between parameters of this status. In work, a pressure and temperature were varied as parameters of system equilibrium. For the description of the system as material object, the maintenance of chemical elements forming it was necessary the nobility only. Internal and interphase interactions are described by modelling thermodynamic parities for which short circuit properties only individual substances - equilibrium components are used.

Thanks to simplicity of the statement, modeling problem the program complex TERRA allows to use a thermodynamic method for studying of the big number of the diversified high-temperature conditions and processes.

In the present study used interface of a program complex:

$\boldsymbol{T E R R} \boldsymbol{A}$. The limiting number of chemical elements from which the investigated system can consist, is equal 50; the number of the condensed phases considered during one calculation, is limited 200, and the quantity of components of the gas phase formed in balance (number of individual substances), can reach 800 . At carrying out of calculations for heterogeneous systems probably use, both models of one-component not mixing up phases, and models of the condensed solutions.

TRIANGLE. Calculations are possible in two modes:

- For isothermal conditions when system equilibrium is set by value of temperature ( $T$, $\mathrm{K})$ and pressure (p, MPa)

- For conditions of adiabatic equilibrium transformation (burning) set in each point of calculation by values of pressure ( $\mathrm{p}, \mathrm{MPa}$ ) and enthalpy of reaction of initial substances (I, $\mathrm{kJ} / \mathrm{kg}$ ).

RECTANGLE. Areas with an identical set of the one-component condensed phases as a result of repeated calculations in the set temperature range for all possible parities of initial substances come to light.

Thermal behavior of oxides, carbides and nitrides investigated in the range of temperatures from $273 \mathrm{~K}$ to $2673 \mathrm{~K}$ at atmospheric pressure $\left(10^{5} \mathrm{~Pa}\right)$. Research of stoichiometric composition in which carbides of transitive metals are formed, carried out in the same conditions. Possible interactions with participation $\mathrm{Ti}, \mathrm{Cr}, \mathrm{C}$ and the alloyed steel 
(Fe70.88C0.12Cr18Ni10Ti1) in atmosphere of inert gas (He, Ar) and air (N53.91014.48Ar0.32) were investigated.

In calculations considered following phases: nitrides $\mathrm{TiN}, \mathrm{CrN}, \mathrm{Cr}_{2} \mathrm{~N}, \mathrm{Fe}_{4} \mathrm{~N}$ and $\mathrm{Fe}_{3} \mathrm{~N}_{4}$, oxides $\mathrm{Cr}_{2} \mathrm{O}_{3}, \mathrm{TiO}_{2}, \mathrm{Ti}_{2} \mathrm{O}_{3}, \mathrm{Ti}_{4} \mathrm{O}_{7}, \mathrm{Ti}_{3} \mathrm{O}_{5}, \mathrm{TiO}, \mathrm{FeO}, \mathrm{Fe}_{3} \mathrm{O}_{4}, \mathrm{Fe}_{2} \mathrm{O}_{3}, \mathrm{NiO}$ and carbides $\mathrm{TiC}$, $\mathrm{Cr}_{3} \mathrm{C}_{2}, \mathrm{Cr}_{7} \mathrm{C}_{3}, \mathrm{Cr}_{23} \mathrm{C}_{6}$ and $\mathrm{Fe}_{3} \mathrm{C}$.

The special attention is given research of phase equilibrium and to revealing of phase transformations sequence and fields of crystallization of co-existing phases in system $\mathrm{TiO}_{2}-\mathrm{Cr}_{2} \mathrm{O}_{3}$-C. Phase balances in all concentration area through $1-5 \mathrm{~mol}$. \% were investigated. Isothermal cuts in the range of temperatures from 773 to $2573 \mathrm{~K}$ and pressure $p=10^{5} \mathrm{~Pa}$ have been simulated. For revealing of the tendency of crystallization of this or that phase, in a concentration triangle put isotherms crystalline fields at one pressure or on isothermal section specified areas of phases taking into account various pressure.

Developed materials are intended for reception of composite heat resisting layers of the titan and chrome carbides on a surface of the alloyed steels at non-vacuum electron-beam melting.

\section{Results of thermodynamic modelling and their discussion}

Into composition of an initial mix entered substances which at heterogeneous interaction in the course of electron-beam melting are capable to form with each other and with a metal basis (Fe-Cr-Ni-Ti) a number of refractory compounds.

\subsection{Synthesis of carbide of titan TiC}

Initially have been simulated reactions in system Ti-C-O $\mathrm{O}_{2}$. In a temperature interval from $1273 \mathrm{~K}$ to $1673 \mathrm{~K}$, it is observed changes of thermodynamic properties (in three stages) on which basis it is possible to estimate size of thermal effect of chemical interaction, a component $\Delta \mathrm{H}$ equal to $-486 \mathrm{~kJ} / \mathrm{mol}$.

Interaction the titan oxide $\mathrm{TiO}_{2}$ with carbon begins with reduction. In mixes have been appear titan oxides $\mathrm{Ti}_{4} \mathrm{O}_{7}(1298 \mathrm{~K})$ and $\mathrm{Ti}_{2} \mathrm{O}_{3}(1548 \mathrm{~K})$. In the condensed phase, an occurrence of the titan carbide is observed at $1948 \mathrm{~K}$, which concentration does not vary to temperature $2173 \mathrm{~K}$, and further there is a decomposition and transition of titan and carbon vapors in a gas phase (Figure 1). And, occurrence of steams of the titan is fixed from temperature $1473 \mathrm{~K}$, and since $1228 \mathrm{~K}$, the gas phase is ionized (Figure 1).

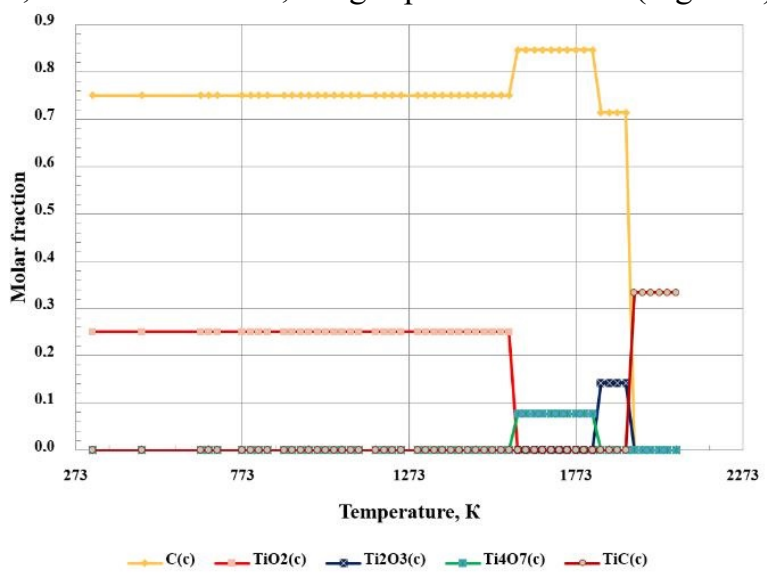

Figure 1. Change of phase composition in the condensed phase in mix $\mathrm{TiO}_{2}: 2 \mathrm{C}$ at atmospheric pressure. 
Synthesis of titan carbide $\mathrm{TiC}$ on air begins at temperature $1248 \mathrm{~K}$ (Figure 2). At this temperature, it is formed oxide $\mathrm{Ti}_{4} \mathrm{O}_{7}$, which turns in oxide $\mathrm{Ti}_{2} \mathrm{O}_{3}(1548 \mathrm{~K})$.

In $\mathrm{s}$ stoichiometric mixture $\mathrm{TiO} 2: 2 \mathrm{C}$ on air a titan nitride $\mathrm{TiN}$ can be formed at temperature $1598 \mathrm{~K}$. The titan nitride is an impurity phase for titan carbide (Figure 2, a). Surplus of carbon $\mathrm{C}$ is necessary the formation of single-phase carbide. Introduction of surplus in number of 0.1 (2.1 mole) leads to formation of single-phase carbide without the nitride TiN, and it is accompanied by increase in a quantity of carbide. It is necessary to notice, that is thus observed, insignificant quantity of the carbon impurity in process of rise in temperature. Possibly, it should call formation of nonstoichiometric carbide $\mathrm{TiC}_{1+\mathrm{x}}$.

Synthesis of titan carbide on alloy steel surface on air also occurs multistage. It is possible to allocate stages of interaction initial oxide $\mathrm{TiO}_{2}$ with carbon with formationoxide $\mathrm{Ti}_{4} \mathrm{O}_{7}(1298 \mathrm{~K})$, oxide $\mathrm{Ti}_{2} \mathrm{O}_{3}(1548 \mathrm{~K})$. Last oxide reacted with nitrogen with formation of titan nitride TiN (1573K) (Figure 3).

Formation of carbide TiC begins at temperature $1648 \mathrm{~K}$.

Especially it is necessary to note behaviour of an alloying component of a steel, namely, chrome. By thermodynamic calculations chrome in reactionary mixes should be the oxide $\mathrm{Cr}_{2} \mathrm{O}_{3}$ (upon temperatures $1348 \mathrm{~K}$ ). Further, oxide are reacted with carbon by formation the carbide $\mathrm{Cr}_{3} \mathrm{C}_{2}$ which then forms carbide $\mathrm{Cr}_{7} \mathrm{C}_{3}(1973 \mathrm{~K})$.

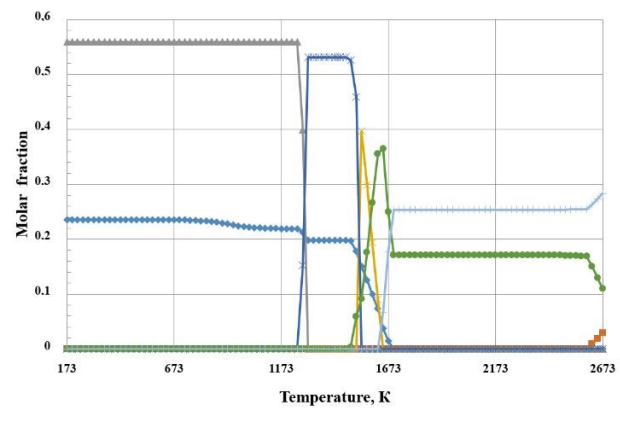

$\rightarrow \mathrm{C}(\mathrm{c})=-\mathrm{TiO}(\mathrm{c}) \rightarrow \mathrm{TiO} 2(\mathrm{c})-\mathrm{Ti2O}(\mathrm{c})-\mathrm{Ti} 4 \mathrm{O} 7(\mathrm{c}) \rightarrow \mathrm{TiN}(\mathrm{c})-\mathrm{TiC}(\mathrm{c})$

a

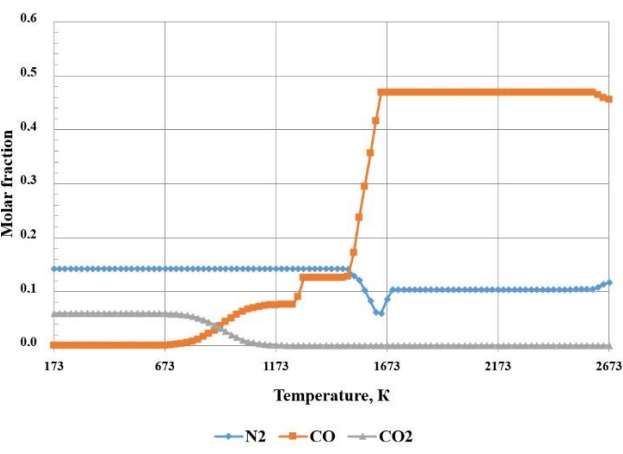

b

Figure 2. Interaction in mixture $\mathrm{TiO}_{2}: 2 \mathrm{C}$ on air: a- condensed phases, b-gas phase.

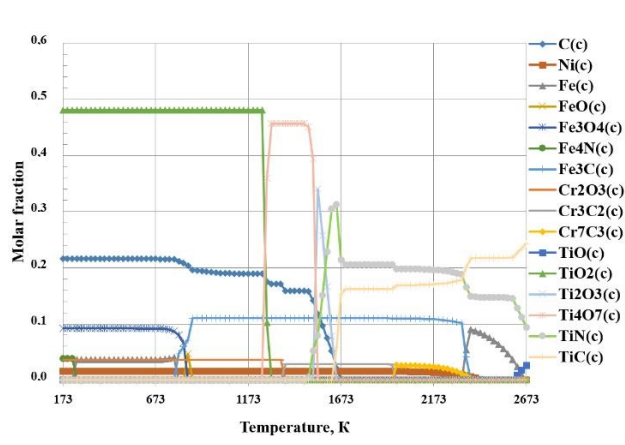

a

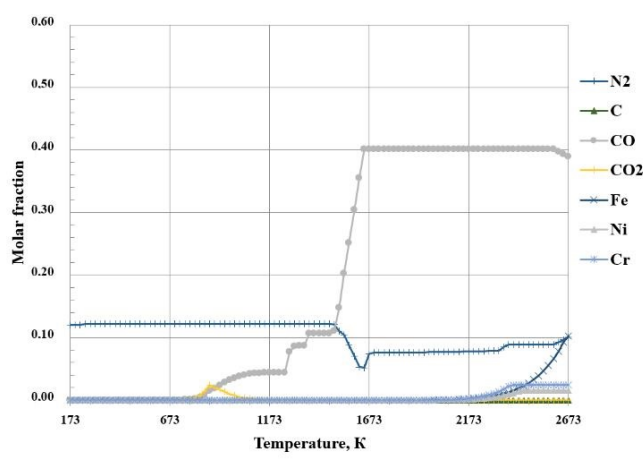

b

Figure 3. Interaction in structure $\mathrm{TiO}_{2}: 2 \mathrm{C}$-alloy steel on air: a-condensed phases, b-gas phase.

As a result of chemical interaction of a reactionary mix with a alloy steel surface on air at temperatures above $1673 \mathrm{~K}$ in products should be present thetitan nitride TiN, carbides $\mathrm{TiC}, \mathrm{Fe}_{3} \mathrm{C}$ and $\mathrm{Cr}_{3} \mathrm{C}_{2}$ which then passes in carbide $\mathrm{Cr}_{7} \mathrm{C}_{3}$. 
Introduction of superfluous quantity of carbon leads to reduction of the maintenance of the titan nitride, and its finishing to 2.2 mole carbon (against 2.1 asking simply on air) calls increase in an exit of carbide titan the from 30.25 to 33.17 mass. \% in a mix of carbides $\mathrm{Fe}_{3} \mathrm{C}$ and $\mathrm{Cr}_{3} \mathrm{C}_{2}$. It is necessary to notice, that carbide $\mathrm{Cr}_{3} \mathrm{C}_{2}$ remains steady and does not pass in carbides of other structures $\left(\mathrm{Cr}_{7} \mathrm{C}_{3}\right.$ and $\left.\mathrm{C}_{6} \mathrm{Cr}_{23}\right)$ (Figure 3 ).

Thus, the presented thermodynamic calculations show on possibility of synthesis of the titancarbide on a surface of the alloyed steel on air from reactionary mix $\mathrm{TiO}_{2}: 2.2 \mathrm{C}$. Carbide TiC should be in a mix with carbides $\mathrm{Fe}_{3} \mathrm{C}$ and $\mathrm{Cr}_{3} \mathrm{C}_{2}$.

\subsection{Composites synthesis on the basis of titan and chrome carbides}

As the maintenance of an alloying impurity (chrome) in the alloyed steel is high (18 mass. $\%)$ represents to stop on interaction of the titan and chrome oxides with carbon. Threefold system $\mathrm{TiO}_{2}-\mathrm{Cr}_{2} \mathrm{O}_{3}-\mathrm{C}$ has been investigated. It is necessary to notice, that system $\mathrm{TiO}_{2}$ $\mathrm{Cr}_{2} \mathrm{O}_{3}$ is studied [24].

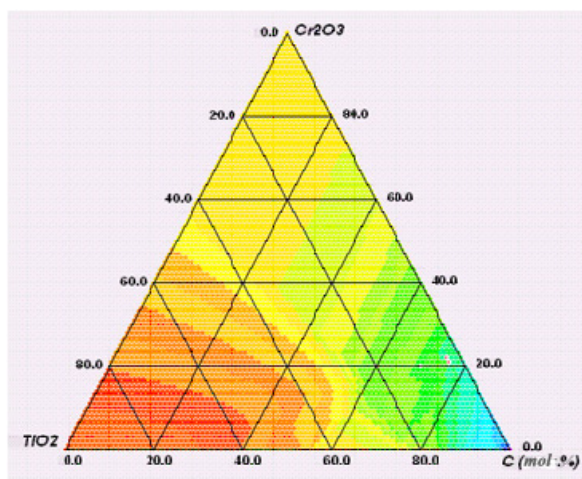

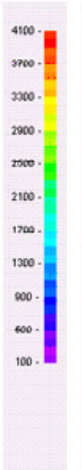
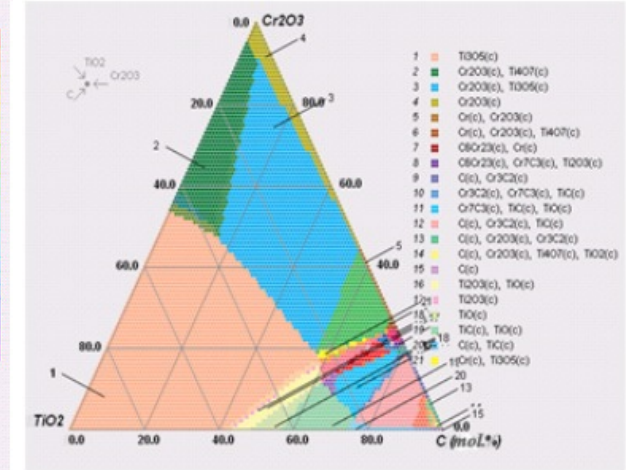

$\mathrm{b}$

Figure 4. Interaction in system $\mathrm{TiO}_{2}-\mathrm{Cr}_{2} \mathrm{O}_{3}-\mathrm{C}\left(\mathrm{p}=10^{5} \mathrm{~Pa}\right)$ : $\mathrm{a}$ - isotherms; $\mathrm{b}$ - equilibrium composition of the condensed phase.

As a result of thermodynamic calculation values of adiabatic temperature Tad and equilibrium composition of products of heterogeneous interaction are defined at this temperature (Figure 4,a). The Adiabatic temperature of the titan and chrome oxides interaction with carbon reaches $3700 \mathrm{~K}$. Phase composition re in an equilibrium conditions is combined (Figure 4, $b$ ).

In Table 1 composition in which formation of carbides of the titan and chrome is possible are resulted.

Table 1. The maintenance of phases (mass. \%) in the condensed phase at $1673 \mathrm{~K}$ on air.

\begin{tabular}{|c|c|c|c|c|c|c|}
\hline $\begin{array}{c}\text { Composition of a mix } \\
\text { for a composite }\end{array}$ & $\mathrm{TiC}$ & $\mathrm{Cr}_{3} \mathrm{C}_{2}$ & $\mathrm{TiN}$ & $\mathrm{Fe}_{3} \mathrm{C}$ & $\mathrm{C}$ & $\mathrm{Ti}_{2} \mathrm{O}_{3}$ \\
\hline $\mathrm{TiO}_{2}: 0.3 \mathrm{Cr}_{2} \mathrm{O}_{3}: 3.3 \mathrm{C}$ & 33.95 & 37.21 & & 14.38 & 7.54 & \\
\hline $0.3 \mathrm{TiO}_{2}: \mathrm{Cr}_{2} \mathrm{O}_{3}: 3.3 \mathrm{C}$ & & 23.08 & 7.10 & 8.92 & & 19.82 \\
\hline
\end{tabular}

Thus, strengthening phases should represent themselves thermodynamic stable refractory compounds of carbides and nitrides of chrome, the titan and iron. Hence, at chemical interaction in the given system the probability of development exothermic interactions in a mode of thermal explosion is rather great. 


\subsection{Formation of composite coating on alloy steel by non-vacuum electron- beam melting}

For experimental test of the thermodynamic calculations by standard methods of x-ray diffraction and scanning electron microscopy researches of phase composition and structure of the composite layers generated non-vacuum electron-beam melting are carried out. The reactionary daub was piled up a previously preformed surface of samples with thickness of 0.5-1 mm. Oxides $\left(\mathrm{Cr}_{2} \mathrm{O}_{3}\right.$ and $\left.\mathrm{TiO}_{2}\right)$, carbon $\mathrm{C}$ (birch charcoal) and the organic binding were entered into the daub composition. Researches spent on samples, the size $80 \times 80 \mathrm{~mm}$ and height $7 \mathrm{~mm}$ executed from the alloyed steel.

The layer thickness made by non-vacuum electron-beam melting was 120-150 microns. Layers are uniform on all thickness. The accurate border is observed has undressed a layerbasis.

According the x-ray analysis (powder diffractometer Phaser 2D Bruker, $\mathrm{CuK} \alpha$ radiation) composite layers have been consists of crystal phases (72.9 mass. \% (sample №1) and 74.5 mass. \% (sample №2) and also contains 27.1 mass. \% and 25.5 mass. \% Xray amorphous phases, accordingly). It is necessary to notice, that at all investigated samples on roentgenograms there are the reflexes belonging to nickel. The nickel maintenance fluctuates from 1.2 to 2.18 mass. \%. Besides, it is possible to observe and lines, which intentificated as martensite, but the maintenance does not exceed them 2 mas $\%$. Occurrence of martensite plates can be observed in austenite grains of an initial metal basis. Occurrence martensite can be connected with hardening processes at cooling of samples after removal of influence of an electron beam. Occurrence in a composite layer of chrome carbides $\mathrm{Cr}_{7} \mathrm{C}_{3}$ and $\mathrm{Cr}_{23} \mathrm{C}_{6}$ also testifies about high temperature in samples as a result of influence of an electron beam (Table 2).

Table 2. Phase composition of layers from reactionary daub on the alloyed steel after non-vacuum electron-beam melting (mass. \%).

\begin{tabular}{|c|c|c|c|c|c|c|c|c|c|}
\hline & $\mathrm{TiC}$ & $\mathrm{Fe}_{3} \mathrm{C}$ & Austenite & $\mathrm{Fe}$ & $\mathrm{Fe}_{3} \mathrm{O}_{4}$ & $\mathrm{Fe}_{2} \mathrm{O}_{3}$ & $\mathrm{Cr}_{3} \mathrm{C}_{2}$ & $\mathrm{Cr}_{7} \mathrm{C}_{3}$ & $\mathrm{Cr}_{23} \mathrm{C}_{6}$ \\
& $00-$ & $00-$ & $00-023-$ & $01-$ & $01-$ & $01-$ & $00-$ & $01-$ & $00-$ \\
& $006-$ & $003-$ & 0298 & $077-$ & $086-$ & $088-$ & $001-$ & $071-$ & $035-$ \\
& 0693 & 0400 & & 7904 & 1344 & 2359 & 1186 & 3789 & 0783 \\
\hline $1 . \mathrm{TiO}_{2}+0.3 \mathrm{Cr}_{2} \mathrm{O}_{3}+3.3 \mathrm{C}$ & 13.16 & 6.33 & 9.40 & 4.97 & 6.11 & 43.95 & 3.31 & 3.85 & 6.80 \\
\hline $2 . \mathrm{TiO}_{2}+2.2 \mathrm{C}$ & 36.12 & 13.19 & 11.34 & 3.55 & 2.38 & 11.57 & - & - & - \\
\hline
\end{tabular}

Besides, as synthesis of the titan and chrome carbides in reactionary daubs on air an oxidation of a metal basis is possible. According to X-ray analysis in samples presence iron oxides and $\mathrm{Fe}_{3} \mathrm{O}_{4}$ and $\mathrm{Fe}_{2} \mathrm{O}_{3}$ is fixed.

Thus, experimental data confirm efficiency of the above-stated method of thermodynamic modelling for receipt of layers by non-vacuum electron-beam melting.

\section{Conclusions}

1. Computer program Terra (working out Bauman state technical university, Trusov B.G.), is effective for thermodynamic modelling and optimization of structure of reactionary mixes of the titan and chrome oxides and carbon for synthesis and out of vacuum electronbeam melting for heat resisting layers on the basis of carbides of transitive metals on the alloyed steels.

2. Interaction between initial oxides with carbon is accompanied by heat significant amount. Calculated adiabatic temperature can reach $3700 \mathrm{~K}$ in reactionary mixes. At formation of strengthening layers on a surface of the alloyed steels have been are selfextending high-temperature synthesis proceeds. 
3. According to experimentally confirmed results of the thermodynamic modelling, formed in process non-vacuum electron-beam melting the strengthening phases represent thermodynamic stable refractory compounds of the titan and chrome carbides and nitrides.

\section{Acknowledgment}

Work supported by the Ministry of Education and Science of Russian Federation under Agreement number 14.577.21.0018 (RFMEFI57714X0018).

\section{References}

[1] B.S. Bokstein M.I. Mendelev, D.J. Srolovitz, Thermodynamics and Kinetics in Materials Science: A Short Cours (Oxford University Press, Oxford 2005)

[2] N. Saunders, A.P. Miodownik, N. Saunders, CALPHAD (Calculation of Phase Diagrams): A Comprehensive Guide (Elsevier Science Ltd., Cambridge, 1998)

[3] M. Hillert, Phase Equilibria, Phase Diagrams and Phase Transformations: Their thermodynamic Basis (Cambridge University Press, Cambridge, 2008)

[4] V. Belov, Thermodynamic modeling: methods, algorithms, programs (Nauchny Mir, Moscow, 2002)

[5] P. Mason, M. Mignanelli, Adv. Mat. Proc. 153, 21 (1998)

[6] L.G. Voroshnin, Multi-component diffusion carbide coatings on iron-carbon alloys (BNTU, Minsk, 2007)

[7] N.P. Novikov, I.P. Borovinskaya, A.G. Merzhanov, Problems of combustion in chemical technology and metallurgy (OICF, Chernogolovka, 1975)

[8] S.S. Mamyan, A.A. Shiryaev, A.G. Merzhanov, J. Eng. Phys. 65, 431 (1993)

[9] A. Shiryaev, International Journal of SHS 4, 351 (1995)

[10] G.B. Sinyarev, Usage of computers for thermodynamic calculations of metallurgic processes (Nauka, Moscow, 1982)

[11] N.A. Vatolin, G.K. Moiseyev, B.G. Trusov, Thermodynamic modeling in hightemperature inorganic systems (Metallurgy, Moscow, 1994)

[12] I. Barin, O. Knacke, Thermochemical Properties of Inorganic Substances (SpringerVerlag, Berlin, 1973)

[13] I. Barin, O. Knacke, O. Kubaschevski, Thermochemical Properties of Inorganic Substances. Supplement (Springer-Verlag, Berlin, 1977)

[14] U.D. Veryatin, Thermodynamic properties of inorganic substances (Atomizdat, Moscow, 1965)

[15] V.P. Glushko, Thermal constants of substances (VINITI, Moscow, 1979)

[16] V.P. Glushko, Thermodynamic properties of individual compounds (Nauka, Moscow, 1982)

[17] I. Barin, Thermochemical Data of Pure Substances (VCH Publishers, New York, 1995)

[18] M.W. Chase Jr., NIST-JANAF Thermochemical Tables, 4th Ed., J. Phys. Chem. Ref. Data, Monograph 9 (1998)

[19] M. Binnewies, E. Milke, Thermochemical Data of Elements and Compounds (Wiley-VCH Verlag GmbH, Weinheim, 2002)

[20] B.B. Khina, A.F. Ilyushchenko, A.V. Belyayev, Powder metallurgy 26, 35 (2003)

[21] T.B. Massalski, H. Okamoto, P.R. Subramanian, L. Kacprzak, Binary Alloy Phase Diagrams (ASM International, Materials Park, 1990)

[22] N.P. Lyakishev, Binary metal systems diagrams (Mashinostroenie, Moscow, 1999)

[23] N.I. Ilinykh, and V.P. Vassiliev, MATEC Web of Conferences 3, 01074 (2013)

[24] S. Riyas, P.N. Mohan Das, Brit. Ceram. Transactions 103, 23 (2004) 